\title{
New Zealander
}

National Cancer Institute

\section{Source}

National Cancer Institute. New Zealander. NCI Thesaurus. Code C126536.

Denotes a person whose ancestry is in the country of New Zealand. 